\title{
Brainstem haematoma due to presumed cryptic telangiectasia
}

\author{
R S HOWARD
}

From the Department of Neurology, St Thomas' Hospital, London, UK

SUMMARY Three patients with primary brainstem haematoma are reported. The clinical presentation suggested an initial diagnosis of pontine tumour in two and demyelination in one patient. The subacute course is characteristic of brainstem haematoma due to presumed cryptic telangiectasia, the abnormal vessels being destroyed by the haemorrhage. These findings emphasise the importance of considering haematoma due to cryptic telangiectasia in the differential diagnosis of subacute brainstem lesions.

Cerebral cryptic arteriovenous malformations are telangiectatic lesions, usually measuring less than $3.5 \mathrm{~cm}$ in maximum dimensions ${ }^{12}$ and characterised by extremely thin walled capillaries with no muscle or elastic tissue. ${ }^{3-6}$

The frequency of cryptic malformations of the brainstem is difficult to establish. They are rarely visible on angiography, do not give rise to symptoms or signs unless haemorrhage occurs and the process of haemorrhage itself frequently destroys the abnormal vessels. McCormick ${ }^{4}$ suggested cryptic telangiectasia within the brainstem are considerably more common than classical arteriovenous malformations, but their frequency has been underestimated by previous necropsy and surgical series.

Three patients with primary brainstem haematoma are now reported. The subacute course emphasises the clinical difficulties in distinguishing haematoma from other causes of subacute brainstem lesions.

\section{Case reports}

Case 1

This 27-year-old lady presented in March 1985 . Following a 'flu like illness three weeks prior to admission, she noticed difficulty reading "because the words seemed to move". One week later she developed diplopia on right lateral gaze which gradually increased in extent. At the same time she developed persistent nausea and vomiting aggravated by postural change. A week prior to admission she developed

Address for reprint requests: Dr RS Howard, Department of Neurology, St Thomas' Hospital, London SE1 7EH, UK.

Received 12 November 1985 and in revised form 14 January 1986. Accepted 25 January 1986 paraesthesiae on the right side of the face and within a few hours these spread to involve the trunk and limbs on the left. On the day prior to admission she noted increasing deafness in the right ear with associated tinnitus.

General examination was unremarkable with no cranial

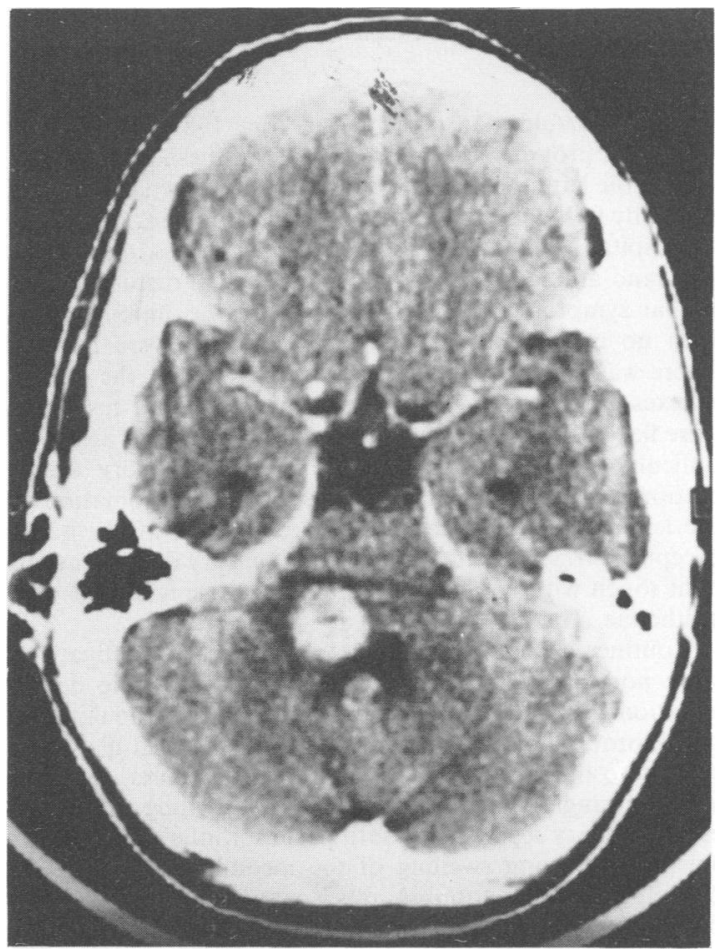

Fig 1 Case 1 CT scan showing a high density lesion lying in the right side of the brainstem. 
bruits. She was fully alert and orientated. The fundi were normal, the right corneal reflex was diminished and there was diminished sensation to touch and pin prick on the right upper lip. There was a right sixth nerve palsy with gaze paretic nystagmus in the left eye on gaze to the right and rotatory nystagmus on upgaze. There was a mild right lower motor neuron facial weakness and mild right sensorineural deafness. There was no motor deficit or reflex change. Sensory examination revealed some decrease of light touch and pin prick appreciation on the left sided limbs and left side of the trunk. Vibration and joint position sense was intact. Routine haematology and biochemistry were normal and an initial diagnosis of pontine glioma was made. A high resolution CT scan (fig 1) showed a well defined slightly irregular hyperdense mass lying in the right side of the brainstem. There was a small area of surrounding low density and only slight contrast enhancement. Vertebral angiography showed the basilar artery to be displaced a little anteriorly but no tumour circulation was demonstrated.

Three weeks later a posterior fossa exploration was performed and this disclosed a heaped up discoloured area in the floor of the IV ventricle; the haematoma was incised and evacuated. The histology revealed only a few hyperchromatic cells which were probably reactive in nature. No abnormal vessels were noted. Postoperatively the right facial weakness was worse but in the subsequent four months this has improved considerably. The postural vomiting recovered completely but the remaining clinical signs were unchanged. Examination six months after operation showed partial resolution of the facial weakness.

\section{CASE 2}

This 27-year-old man presented in June 1984 with a 3 day history of progressively worsening paraesthesiae and numbness in the left limbs and left side of the trunk which came on suddenly following a bout of hiccough. Following admission to hospital he developed progressive clumsiness in using the left hand and leg. There had been no visual disturbance or bulbar symptoms. General examination was unremarkable with no cranial bruits. The cranial nerves were normal. There was normal tone and power in the limbs, the tendon reflexes were pathologically brisk but the plantar responses were flexor. There was finger-nose ataxia in the left arm with difficulty in performing fine movements. Sensory examination showed a widening of two point discrimination in the left hand; subjectively the entire left side of the body, except the trigeminal territory, had a sensory disturbance to light touch with cutaneous stimulation causing diffuse dysaesthesiae. The gait was normal.

Routine haematological and biochemical investigations were normal and an initial diagnosis of possible demyelination was made. A CT scan (fig 2) showed a circular area of abnormal high density at the level of the medulla, lying slightly to the left. There was slight enhancement. Bilateral vertebral angiography showed lateral stretching of the lateral medullary segments of both posterior inferior cerebellar arteries indicating swelling of the medulla. There was no pathological circulation. A myelogram showed backward displacement of the vallecula confirming the presence of a mass within the medulla.

A posterior fossa craniotomy was performed; the left half of the medulla was swollen by dark, discoloured blood. This

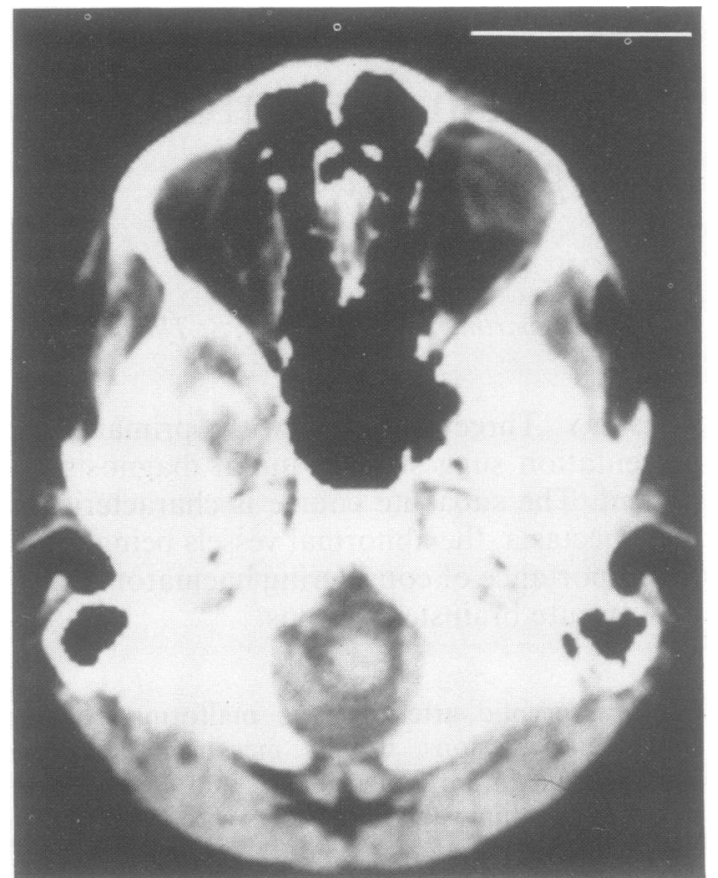

Fig 2 Case 2 CT scan showing a high density lesion lying in the left side of the medulla.

was incised and the histology showed only small amounts of necrotic tissue. No abnormal vessels were noted.

One year after operation there has been considerable improvement in the neurological deficit with only minimal dysaesthesiae in the left arm and leg.

\section{CASE 3}

This 22-year-old lady presented in September 1983. Eight days before admission she awoke with a severe headache. On the next day she developed paraesthesiae in the left arm and leg which worsened over the subsequent 48 hours. Over the following three days she developed progressive dysarthria, difficulty looking to the right and weakness of the left arm and leg with some difficulty walking. At the referring hospital a lumbar puncture was performed and within a few hours she became more drowsy and the dysarthria worsened. She was subsequently transferred to the neurological centre.

General examination was unremarkable; there were no cranial bruits. She was very drowsy on admission with dysarthria but was fully orientated. The fields were full, pupils reacted normally and the fundi were normal. The eyes were deviated to the left and did not cross the midline with gaze paretic nystagmus on attempted right gaze. There was diminished pin prick appreciation over all divisions of the right trigeminal nerve and a right lower motor neuron facial weakness. The lower cranial nerves were normal. The tone was increased in the left leg and there was marked poverty of movement of the left limbs which was not formally assessable because of her conscious state. The reflexes were pathol- 


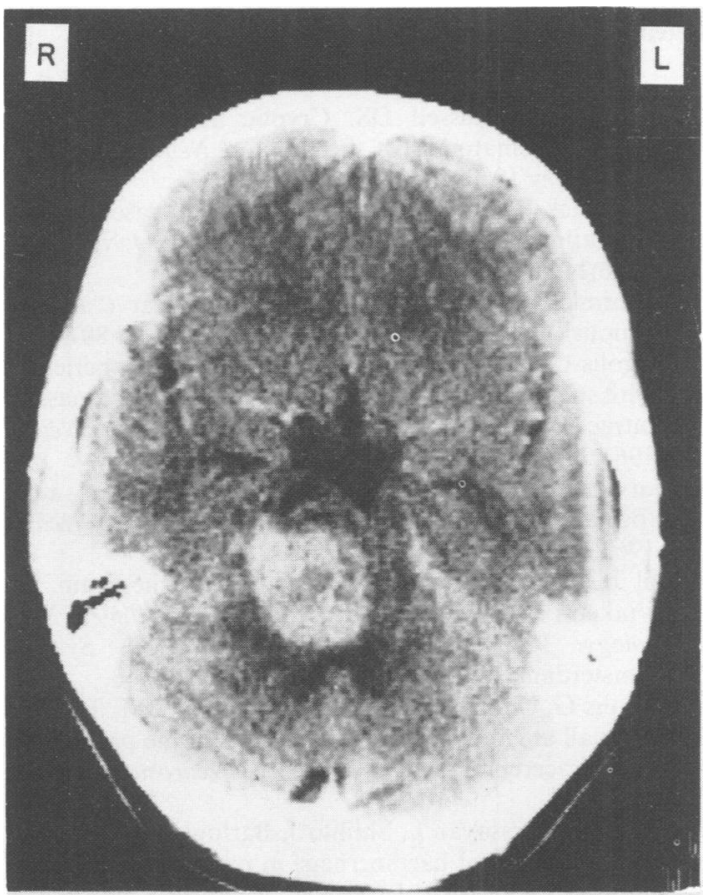

Fig 3 Case 3 CT scan showing a high density lesion lying in the right side of the pons.

ogically brisk on the left with an extensor plantar response. There was a left hemisensory loss to pin prick and dense left posterior column loss with pseudo-athetosis.

Routine haematology, clotting and biochemical screen were normal and an initial diagnosis of pontine glioma was made. A CT scan (fig 3) showed a high density lesion in the right side of the pons causing backward displacement and deformity of the IV ventricle. There was no definite enhancement. A vertebral angiogram showed that the tonsillar loops of both posterior inferior cerebellar arteries were displaced downwards due to tonsillar herniation. The right inferior cerebellar artery and superior cerebellar artery were both stretched and displaced around a mass lesion. There was no evidence of pathological circulation.

Over the following two weeks she became more alert but the neurological signs deteriorated. The disc margins became blurred and she was unable to deviate her eyes to the right or left although upgaze and downgaze were preserved with gaze evoked nystagmus. The jaw was noted to deviate to the right and there was increased spasticity and pyramidal weakness on the left. Both plantar responses were extensor. She underwent posterior fossa craniotomy and a right sided pontine haematoma was found. This was evacuated, the histology showing blood clot only, with no abnormal vessels being noted.

One month following surgery there was considerable improvement in the neurological signs and by the time of discharge the fundi, the extraocular eye movements and the trigeminal nerve function were normal. There was mild left facial weakness but the remaining cranial nerves were intact.
There was mild ataxia of gait and limbs with minimal pyramidal weakness on the left. However, there was profound residual posterior column sensory loss in the left arm and leg. Two years following surgery these abnormalities have improved considerably and there is only a mild deficit of joint position appreciation in the left arm.

\section{Discussion}

Margolis ${ }^{7}$ described four young patients with spontaneous intracerebral haematoma arising from rupture of small vascular malformations. He noted a number of earlier reports of such haemorrhages which had several features in common; in particular they occurred in the younger age group, in the absence of any known predisposing factors and with no demonstrable anatomical cause for the bleeding. Crawford and Russell ${ }^{1}$ introduced the term "cryptic arteriovenous and venous haematoma of the brain" to describe small telangiectatic lesions found in 20 patients at necropsy. In a necropsy series of 164 patients with posterior fossa angiomata, McCormick ${ }^{2}$ showed that the most common type of malformation in the brainstem was telangiectasia, owing to their relative frequency in the pons. He suggested that cryptic telangiectasia are considerably more common than classical arteriovenous malformations, but their frequency had been previously underestimated by surgical and necropsy studies because the abnormal vessels are usually destroyed by the haemorrhage. Although none of the 27 cases with pontine telangiectasia in his series suffered fatal haemorrhage, he suggested the lesions may account for a proportion of primary pontine haematoma. ${ }^{4} \mathrm{~A}$ number of anecdotal reports have further suggested that the clinical presentation of pontine haematoma due to rupture of cryptic telangiectasia differs from primary pontine haemorrhage.

The three patients described in this series fit the consistent clinical pattern of this condition. All the patients were normotensive and presented in the third decade with the subacute onset of brainstem symptoms and signs over a period varying from three days to three weeks. They suffered hemisensory disturbances and in two patients this was the presenting symptom. Both patients with pontine haematoma developed disturbances of gaze, either as VI nerve or pontine gaze palsy, and facial nerve palsies. An initial diagnosis of pontine glioma was made in two cases and demyelination in one patient. The CT scan appearance of high density lesions in the brainstem suggested the presence of haematoma; in two patients the haematoma impinged on the IV ventricle without rupturing the wall. Angiography showed vessel displacement appropriate to the site of the mass lesion but no abnormalities of vasculature. All the patients 
underwent posterior fossa craniotomy and evacuation of the haematoma although there was clear evidence of progressive deterioration in only one patient. The walls of the haematomas were not biopsied but no abnormal vasculature was found on histological examination of the tissue evacuated. Postoperatively all the patients continued to show moderate neurological deficits, reflecting the preoperative abnormalities, which are progressively resolving.

The natural history of pontine haematoma is uncertain as most reports in the literature concern either post mortem studies or surgical evacuation. Recent reports have indicated that spontaneous pontine haemorrhage may carry a better prognosis than suggested by earlier necropsy reports. ${ }^{15-17}$ Certainly before CT was available a number of cases of pontine haematoma may have been misdiagnosed as glioma and treated with radiotherapy as in the patient described by Michael et al. ${ }^{24}$ O'Laiore et al ${ }^{12}$ have reported successful evacuation in five of six patients and suggested that untreated pontine haematoma is universally fatal. However, a number of series cited by Masiyama ${ }^{14}$ have reported that the mortality of pontine haemorrhage is between $30 \%$ and $68.7 \%$ and they found a strong correlation between prognosis and the transverse diameter of the haematoma on CT scan in 26 cases of pontine haemorrhage.

Brainstem haematomas may be misdiagnosed as other causes of brainstem lesions because the clinical course is usually subacute in onset and slowly progressive with occasional remissions and relapses. These diagnoses may include multiple sclerosis, brainstem encephalitis, infarction, granuloma and primary brainstem glioma or metastases. ${ }^{8-1325}$. There have been several recent reports of successful surgical evacuation of pontine haematoma. ${ }^{10-1218-22}$ The steady progression of symptoms or the exclusion of tumour may be indications for surgical treatment whenever feasible. However, if the clinical state is stable and the cryptic telangiectasia is destroyed there may be a role for conservative management.

Because the abnormal vasculature is frequently destroyed by the haemorrhage, the diagnosis of brainstem haematoma due to cryptic telangiectasia is often circumstantial, based on the subacute clinical course and CT scan findings. The cases reported in this series emphasise the importance of considering haematoma in the differential diagnosis of any subacute brainstem lesion.

I thank Professor L Symon, Mr JJ Maccabe, Dr MD O'Brien and Dr R Ross Russell for allowing me to report patients under their care and for their kind assistance in the preparation of the manuscript. I also thank Miss V Spencer for her secretarial assistance.

\section{References}

${ }^{1}$ Crawford JV, Russell DS. Cryptic arteriovenous and venous haematomas of the brain. J Neurol Neurosurg Psychiatry 1952;19:1-11.

${ }^{2}$ McCormick WF, Nofzinger JD. "Cryptic" vascular malformations of the central nervous system. J Neurosurg 1966;24:865-75.

${ }^{3}$ McCormick WF. The pathology of vascular ("arteriovenous") malformation. J Neurosurg 1966;24:807-16.

${ }^{4}$ Margolis G, Odom G, Woodhall B. Further experiences with small vascular malformations as a cause of massive intracerebral bleeding. $J$ Neuropathol Exp Neurol 1961;20:161-8.

${ }^{5}$ Courville CB. Morphology of small vascular malformations of the brain. J Neuropathol Exp Neurol 1963;22:274-84.

${ }^{6}$ Pool JL. Arteriovenous malformations of the brain. In: Vinken PJ, Bruyn GW, eds. Handbook of Clinical Neurology: Vascular Diseases of the Nervous System. Amsterdam: North Holland Inc, 1972:227-66.

${ }^{7}$ Margolis G, Odom GL, Woodhall B, Bloor BM. The role of small angiomatous malformations in the production of intracerebral haematomas. $J$ Neurosurg 1951;8: 564-75.

${ }^{8}$ Abroms IF, Yessayan L, Shillito J, Barlow CF. Spontaneous intracerebral haemorrhage in patients suspected of multiple sclerosis. J Neurol Neurosurg Psychiatry 1971;34:157-62.

${ }^{9}$ Teilmann K. Haemangiomas of the pons. Arch Neurol Psychiatry 1953;69:208-23.

${ }^{10} \mathrm{Kempe}$ LG. Surgical removal of an intramedullary haematoma simulating Wallenberg's syndrome. J Neurol Neurosurg Psychiatry 1964;27:78-80.

${ }^{11}$ La Torre E, Delitala A, Sorano V. Haematoma of the quadrigeminal plate. J Neurosurg 1978;49:610-3.

${ }^{12}$ O'Laoire SA, Crockard HA, Thomas DGT, Gordon DS. Brain stem haematoma. A report of six surgically treated cases. J Neurosurg 1982;56:222-7.

${ }^{13}$ Wolf PA, Rosman NP, New PFJ. Multiple small cryptic venous angiomas of the brain mimicking cerebral metastases. A clinical pathology and angiographic study. Neurology 1967;17:491-501.

${ }^{14}$ Masiyama S, Nijzuma H, Suzuki J. Pontine haemorrhage: a clinical analysis of 26 cases. J Neurol Neurosurg Psychiatry 1985;48:658-62.

${ }^{15}$ Lavi E, Rothman S, Reches A. Primary pontine haemorrhage with complete recovery. Arch Neurol 1981;38:320-1.

${ }^{16}$ Payne HA, Maravilla KR, Levingstone A, et al. Recovery from primary pontine haemorrhage. Ann Neurol 1978;4:557-8.

${ }^{17}$ Dinsdale HB. Spontaneous haemorrhage in the posterior fossa. Arch Neurol 1964;10:98-115.

${ }^{18} \mathrm{Koos}$ WT, Sunder Plassman M, Salah S. Successful removal of a large intrapontine haematoma. $J$ Neurosurg 1969;31:690-4.

${ }^{19}$ Arseni C, Stanciu M. Primary haematomas of the brain stem. Acta Neurochirurg 1973;28:323-30.

${ }^{20}$ Doczi T, Thomas DGT. Successful removal of an intrapontine haematoma. J Neurol Neurosurg Psychiatry 
1979;42:1058-61.

${ }^{21}$ Murphy MG. Successful evacuation of acute pontine haematoma. J Neurosurg 1972;37:224-5.

${ }^{22}$ Scott BB, Seeger JF, Schneider RC. Successful evacuation of a pontine haematoma secondary to rupture of a pathologically diagnosed "cryptic" vascular malformation. J Neurosurg 1973;39:104-8.

${ }^{23}$ McCormick WF, Hardman JM, Boulter TR. Vascular malformations ("angiomas") of the brain, with special reference to those occurring in the posterior fossa. $J$ Neurosurg 1968;28:241-51.

${ }^{24}$ Michael JC, Levin PM. Multiple telangiectases of the brain. A discussion of hereditary factors in their development. Archs Neurol Psychiatry 1936;36:514-29.

${ }^{25}$ Stahl SM, Johnson KP, Malamud N. The clinical and pathological spectrum of brain-stem vascular malformations. Long term course simulates multiple sclerosis. Arch Neurol 1980;37:25-9. 